\title{
Ćirić types nonunique fixed point theorems on partial metric spaces
}

\author{
Erdal Karapınar ${ }^{\mathrm{a}, *}$ \\ ${ }^{a}$ Department of Mathematics, Atilim University 06836, Incek, Ankara, Turkey \\ This paper is dedicated to Professor Ljubomir Ćirić \\ Communicated by Professor V. Berinde
}

\begin{abstract}
Given a certain type of operator on a partial metric space, new Ćirić types, non-unique fixed point theorems, generalizing the related work of Ćirić [On some maps with a non-unique fixed point,Publications de L'Institut Mathématique, 17 (1974), 52-58], are proved. (C)2012 NGA. All rights reserved.
\end{abstract}

Keywords: Partial metric spaces, Fixed point theorem, Orbital continuity

2010 MSC: 46T99, 54H25, 47H10, 54E50

\section{Introduction and Preliminaries}

The existence and uniqueness of fixed points of operators have been a subject of great interest since the work of Banach [8] on the topic first appeared in 1922. Many similar results for operators on various types of spaces such as metric spaces, quasi-metric spaces (see e.g. [9, 14]), cone metric spaces (see e.g. [16, 18]), Menger (statistical metric) spaces (see e.g. [30]), fuzzy metric spaces (see e.g [24]) have been obtained. In [28, 29], Matthews introduced a new space called Partial metric space (PMS). On this space, he proved a fixed point theorem which is an analog of the Banach fixed point theorem. Later some interested authors showed that partial metric spaces have many applications both in mathematics and computer science (see. e.g. [23, 25, 31, 35, 36]). Recently, some more results on fixed point theory on PMS appeared in [5, 6, 17, 10, 15, 21, 17, 20, 32, 33.

The definition of partial metric space is given by Matthews (See [28] ) as follows:

Definition 1.1. Let $X$ be a nonempty set and let $p: X \times X \rightarrow[0, \infty)$ satisfy

\footnotetext{
* Corresponding author

Email addresses: erdalkarapinar@yahoo.com (Erdal Karapınar), ekarapinar@atilim.edu.tr (Erdal Karapınar)
} 
$(P 1) x=y \Leftrightarrow p(x, x)=p(y, y)=p(x, y)$

$(P 2) p(x, x) \leq p(x, y)$

(P3) $p(x, y)=p(y, x)$

(P4) $p(x, y) \leq p(x, z)+p(z, y)-p(z, z)$

for all $x, y$ and $z \in X$. Then the pair $(X, p)$ is called a partial metric space and $p$ is called a partial metric on $X$.

The usual metric spaces are closely connected to partial metric spaces. One can easily show that the function $d_{p}: X \times X \rightarrow \mathbb{R}^{+}$defined as

$$
d_{p}(x, y)=2 p(x, y)-p(x, x)-p(y, y)
$$

satisfies the conditions of a metric on $X$, therefore it is a (usual) metric on $X$. Note also that each partial metric $p$ on $X$ generates a $T_{0}$ topology $\tau_{p}$ on $X$, whose base is a family of open $p$-balls $\left\{B_{p}(x, \epsilon): x \in X, \epsilon>0\right\}$ where $B_{p}(x, \epsilon)=\{y \in X: p(x, y) \leq p(x, x)+\epsilon\}$ for all $x \in X$ and $\epsilon>0$. Some fundamental concepts like convergence, Cauchy sequence, completeness and continuity in a partial metric space are defined as follows [28].

Definition 1.2. (See e.g.[17, 28, 29])

1. A sequence $\left\{x_{n}\right\}$ in the PMS $(X, p)$ converges to the limit $x$ if and only if $p(x, x)=\lim _{n \rightarrow \infty} p\left(x, x_{n}\right)$.

2. A sequence $\left\{x_{n}\right\}$ in the PMS $(X, p)$ is called a Cauchy sequence if $\lim _{n, m \rightarrow \infty} p\left(x_{n}, x_{m}\right)$ exists and is finite.

3. A PMS $(X, p)$ is called complete if every Cauchy sequence $\left\{x_{n}\right\}$ in $X$ converges with respect to $\tau_{p}$, to a point $x \in X$ such that $p(x, x)=\lim _{n, m \rightarrow \infty} p\left(x_{n}, x_{m}\right)$.

4. A mapping $f: X \rightarrow X$ is said to be continuous at $x_{0} \in X$ if for every $\epsilon>0$, there exists $\delta>0$ such that $F\left(B_{p}\left(x_{0}, \delta\right)\right) \subseteq B_{P}\left(F x_{0}, \epsilon\right)$.

The following three lemmas on partial metric spaces play crucial roles in the proof of the main results of this paper. Their proofs are easily accessible in the literature or can be derived by elementary means (see e.g. [1, 2, 6, 19, 28, 29]).

\section{Lemma 1.3.}

1. A sequence $\left\{x_{n}\right\}$ is a Cauchy sequence in the PMS $(X, p)$ if and only if it is a Cauchy sequence in the metric space $\left(X, d_{p}\right)$.

2. A PMS $(X, p)$ is complete if and only if the metric space $\left(X, d_{p}\right)$ is complete. Moreover

$$
\lim _{n \rightarrow \infty} d_{p}\left(x, x_{n}\right)=0 \Leftrightarrow p(x, x)=\lim _{n \rightarrow \infty} p\left(x, x_{n}\right)=\lim _{n, m \rightarrow \infty} p\left(x_{n}, x_{m}\right)
$$

Lemma 1.4. Assume $x_{n} \rightarrow z$ as $n \rightarrow \infty$ in a PMS $(X, p)$ such that $p(z, z)=0$. Then we have $\lim _{n \rightarrow \infty} p\left(x_{n}, y\right)=p(z, y)$ for every $y \in X$.

Lemma 1.5. Let $(X, p)$ be a PMS. Then

(A) If $p(x, y)=0$ then $x=y$.

(B) If $x \neq y$, then $p(x, y)>0$.

For our purposes, we need to recall the definition of an orbit of a self-mapping. Let $T$ be a self-mapping on a partial metric space $(X, p)$. For $Y \subset X$ and for each $x \in X$ we set (cf.[12])

1. $\delta(Y)=\sup \{p(x, y): x, y \in Y\}$,

2. $O(x, n)=\left\{x, T x, T^{2} x, \cdots, T^{n} x\right\}$ for $n \in \mathbb{N}$, 
3. $O(x, \infty)=\left\{x, T x, T^{2} x, \cdots,\right\}$.

Definition 1.6. (cf.[12])

1. Let $(X, p)$ be a PMS. A map $T: X \rightarrow X$ is called orbitally continuous if

$$
\lim _{i, j \rightarrow \infty} p\left(T^{n_{i}} x, T^{n_{j}} x\right)=\lim _{i \rightarrow \infty} p\left(T^{n_{i}} x, z\right)=p(z, z)
$$

implies

$$
\lim _{i, j \rightarrow \infty} p\left(T T^{n_{i}} x, T T^{n_{j}} x\right)=\lim _{i \rightarrow \infty} p\left(T T^{n_{i}} x, T z\right)=p(T z, T z)
$$

for each $x \in X$.

2. A PMS $(X, p)$ is called orbitally complete if every Cauchy sequence $\left\{T^{n_{i}} x\right\}_{i=1}^{\infty}$ converges in $(X, p)$, that is, if

$$
\lim _{i, j \rightarrow \infty} p\left(T^{n_{i}} x, T^{n_{j}} x\right)=\lim _{i \rightarrow \infty} p\left(T^{n_{i}} x, z\right)=p(z, z)
$$

Remark 1.7. It is clear that orbital continuity of $T$ implies orbital continuity of $T^{m}$ for any $m \in \mathbb{N}$.

The concept of non-unique fixed point was introduced by Ćirić (see [12, 11]). Following him, many interesting papers have appeared (see e.g. [3, 4, 13, 22, 26, 27, 34, 37]) The aim of this paper present some non-unique fixed point theorems in the context of partial metric spaces.

\section{Main Results}

In this section we give some non-unique fixed point theorems for partial metric spaces.

Theorem 2.1. Let $(X, p)$ be a partial metric space. Let $T: X \rightarrow X$ be an orbitally continuous self-mapping on $X$ where $X$ is $T$-orbitally complete. If $T$ satisfies the inequality

$$
\min \{p(T x, T y), p(x, T x), p(y, T y)\} \leq k p(x, y)
$$

for all $x, y \in X$ and for some $k \in(0,1)$, then for each $x \in X$ the sequence $\left\{T^{n} x\right\}$ converges to a fixed point of $T$.

Proof. Take an arbitrary $x_{0} \in X$. Let us define the sequence

$$
x_{n+1}=T x_{n}, \quad n=0,1,2, \ldots
$$

If there exists a positive integer $n$ such that $x_{n}=x_{n+1}$, then $x_{n}$ is a fixed point of $T$. Hence we are done.

Suppose that $x_{n} \neq x_{n+1}$ for each $n=0,1,2, \cdots$. Substituting $x=x_{n}$ and $y=x_{n+1}$ in (2.1) we obtain the inequality

$$
\min \left\{p\left(T x_{n}, T x_{n+1}\right), p\left(x_{n}, T x_{n}\right), p\left(x_{n+1}, T x_{n+1}\right)\right\} \leq k p\left(x_{n}, x_{n+1}\right)
$$

which implies that

$$
\min \left\{p\left(x_{n}, x_{n+1}\right), p\left(x_{n+1}, x_{n+2}\right)\right\} \leq k p\left(x_{n}, x_{n+1}\right) .
$$

Since we assume $k \in[0,1)$, the inequality (2.3) implies that $p\left(x_{n+1}, x_{n+2}\right) \leq k p\left(x_{n}, x_{n+1}\right)$ for every $n=$ $0,1,2, \cdots$. Thus, we get

$$
p\left(x_{n+1}, x_{n+2}\right) \leq k p\left(x_{n}, x_{n+1}\right) \leq k^{2} p\left(x_{n-1}, x_{n}\right) \leq \cdots \leq k^{n+1} p\left(x_{0}, x_{1}\right) .
$$

We claim that $\left\{x_{n}\right\}$ is a Cauchy sequence. Without loss of generality assume that $n>m$. Then, using (2.4) and the triangle inequality $(P 4)$ for partial metric we have

$$
\begin{aligned}
& 0 \leq p\left(x_{n}, x_{m}\right) \leq p\left(x_{n}, x_{n-1}\right)+p\left(x_{n-1}, x_{n-2}\right)+\cdots+p\left(x_{m+1}, x_{m}\right) \\
& -\left[p\left(x_{n-1}, x_{n-1}\right)+p\left(x_{n-2}, x_{n-2}\right)+\cdots p\left(x_{m+1}, x_{m+1}\right)\right] \\
& \leq p\left(x_{n}, x_{n-1}\right)+p\left(x_{n-1}, x_{n-2}\right)+\cdots+p\left(x_{m+1}, x_{m}\right) \\
& \leq\left[k^{n-1}+k^{n-2}+\cdots k^{m}\right] p\left(x_{0}, x_{1}\right) \\
& =k^{m} \frac{1-k^{n-m}}{1-k} p\left(x_{0}, x_{1}\right) .
\end{aligned}
$$


Hence, $\lim _{n, m \rightarrow \infty} p\left(x_{n}, x_{m}\right)=0$. That is, $\left\{x_{n}\right\}$ is a Cauchy sequence in $(X, p)$. By Lemma 1.3, $\left\{x_{n}\right\}$ is also Cauchy in $\left(X, d_{p}\right)$. In addition, since $(X, p)$ is complete, $\left(X, d_{p}\right)$ is also complete. Thus there exists $z \in X$ such that $x_{n} \rightarrow z$ in $\left(X, d_{p}\right)$. Moreover, by Lemma 1.3

$$
p(z, z)=\lim _{n \rightarrow \infty} p\left(z, x_{n}\right)=\lim _{n, m \rightarrow \infty} p\left(x_{n}, x_{m}\right)=0
$$

which implies that

$$
\lim _{n \rightarrow \infty} d_{p}\left(z, x_{n}\right)=0 .
$$

Next we will show that $z$ is the fixed point of $T$. Notice that we have $p(z, z)=0$ due to (2.6). Substituting $x=x_{n}$ and $y=z$ in 2.1) we obtain

$$
\min \left\{p\left(T x_{n}, T z\right), p\left(x_{n}, T x_{n}\right), p(z, T z)\right\} \leq k p\left(z, x_{n}\right) .
$$

Then it follows that

$$
\min \left\{p\left(x_{n+1}, T z\right), p\left(x_{n}, x_{n+1}\right), p(z, T z)\right\} \leq k p\left(z, x_{n}\right) .
$$

Taking limit as $n \rightarrow \infty$, we obtain

$$
p(z, T z) \leq 0
$$

using (2.6) and Lemma 1.4. Thus, $p(z, T z)=0$. Using (1.1), we end up with

$$
0 \leq d_{p}(z, T z)=2 p(z, T z)-p(z, z)-p(T z, T z)=-p(T z, T z) \leq 0 .
$$

Hence, $d_{p}(z, T z)=0$. In particular, we obtain $z=T z$, which completes the proof.

Example 2.2. Let $X=\mathbb{R}^{+}$and $p(x, y)=\max \{x, y\}$ then $(X, p)$ is a PMS (See e.g. [28, 29].) Suppose $T: X \rightarrow X$ such that $T x=\frac{x^{2}}{1+3 x}$ for all $x \in X$. Without loss of generality assume $x \geq y$. Then

$$
\begin{gathered}
p(T x, T y)=\max \left\{\frac{x^{2}}{1+3 x}, \frac{y^{2}}{1+3 y}\right\}=\frac{x^{2}}{1+3 x} \\
p(T x, x)=\max \left\{\frac{x^{2}}{1+3 x}, x\right\}=x \\
p(y, T y)=\max \left\{y, \frac{y^{2}}{1+3 y}\right\}=y \\
p(x, y)=\max \{x, y\}=x \\
\min \{p(T x, T y), p(x, T x), p(y, T y)\}=\min \left\{\frac{x^{2}}{1+3 x}, x, y\right\}=\min \left\{\frac{x^{2}}{1+3 x}, y\right\}
\end{gathered}
$$

For $k=\frac{1}{2}$, all conditions of Theorem 2.1. Indeed, if $\min \left\{\frac{x^{2}}{1+3 x}, y\right\}=\frac{x^{2}}{1+3 x} \leq \frac{x}{2}$. If $\min \left\{\frac{x^{2}}{1+3 x}, y\right\}=y$ then $y \leq \frac{x^{2}}{1+3 x}$ and hence $y \leq \frac{x^{2}}{1+3 x} \leq \frac{x}{2}$. Notice that $x=0$ is the fixed point of $T$.

Theorem 2.3. Let $T: X \rightarrow X$ be an orbitally continuous mapping on T-orbitally complete PMS $(X, d)$ and $\varepsilon>0$. Suppose that there exists a point $x_{0} \in X$ such that $p\left(x_{0}, T^{n}\left(x_{0}\right)\right)<\varepsilon$ for some $n \in \mathbb{N}$ and that $T$ satisfies the condition

$$
0<p(x, y)<\varepsilon \Rightarrow \min \{p(x, T(x)), p(T(x), T(y)), p(T(y), y)\} \leq k p(x, y)
$$

for all $x, y \in X$ and for some $k<1$. Then, $T$ has a periodic point.

Proof. Set $M=\left\{n \in \mathbb{N}: p\left(x, T^{n}(x)\right)<\varepsilon:\right.$ for $\left.x \in X\right\}$. By the assumption of the theorem $M \neq \emptyset$. Let $m=\min M$ and $x \in X$ such that $p\left(x, T^{m}(x)\right)<\varepsilon$. There are two cases to consider: $m=1$ or $m \geq 2$.

Suppose that $m=1$, that is, $p(x, T(x))<\varepsilon$. By replacing $y=T(x)$ in $(2.9)$, one can get

$$
\min \{p(x, T(x)), p(T(x), T(T(x))), p(T(T(x)), T(x))\} \leq k p(x, T(x)) .
$$


The case $p(x, T(x)) \leq k p(x, T(x))$ provides a contraction due to the fact that $k<1$. Thus, $p(T(x), T(T(x)))=$ $p\left(T(x), T^{2}(x)\right) \leq k p(x, T(x))$. As in the proof of Theorem 2.1. one can consider the iterative sequence $x_{n+1}=T\left(x_{n}\right), x=x_{0}$, and observe that $T z=z$ for some $z \in X$.

Suppose $m \geq 2$. This is equivalent to stating that the condition

$$
p(T(y), y) \geq \varepsilon
$$

holds for each $y \in X$. Then, from $p\left(x, T^{m}(x)\right)<\varepsilon$ and $(2.9)$ it follows that

$$
\min \left\{p(x, T(x)), p\left(T(x), T\left(T^{m}(x)\right)\right), p\left(T\left(T^{m}(x)\right), T^{m}(x)\right)\right\} \leq k p\left(x, T^{m}(x)\right) .
$$

Since $T^{m}(x) \in X$, one has $p\left(T\left(T^{m}(x)\right), T^{m}(x)\right)=p(T(w), w)$ when we rename $T^{m}(x)=w$. Regarding (2.10), we obtain $p(T(w), w)=p\left(T\left(T^{m}(x)\right), T^{m}(x)\right) \geq \varepsilon$ and $p(T(x), x) \geq \varepsilon$. Thus,

$$
\min \left\{p(x, T(x)), p\left(T(x), T\left(T^{m}(x)\right)\right), p\left(T\left(T^{m}(x)\right), T^{m}(x)\right)\right\}=p\left(T(x), T^{m+1}(x)\right) .
$$

In particular,

$$
p\left(T(x), T^{m+1}(x)\right) \leq k p\left(x, T^{m}(x)\right)
$$

Recursively, one can get

$$
p\left(T^{2}(x), T^{m+2}(x)\right) \leq p\left(T(x), T^{m+1}(x)\right) \leq k^{2} p\left(x, T^{m}(x)\right) .
$$

Proceeding in this way, for each $s \in \mathbb{N}$, one can obtain

$$
p\left(T^{s}(x), T^{m+s}(x)\right) \leq p\left(T^{s-1}(x), T^{m+s-1}(x)\right) \leq \cdots \leq k^{s} p\left(x, T^{m}(x)\right) .
$$

Thus, for the recursive sequence $x_{n+1}=T^{m}\left(x_{n}\right)$ where $x_{0}=x$,

$$
p\left(x_{n}, x_{n+1}\right)=p\left(T^{n m}\left(x_{0}\right), T^{(n+1) m}\left(x_{0}\right)\right)=p\left(T^{n m}\left(x_{0}\right), T^{m+n m}\left(x_{0}\right)\right) \leq k^{n m} p\left(x_{0}, T^{m}\left(x_{0}\right)\right) .
$$

By using the triangle inequality (P4), for any $s \in \mathbb{N}$, one can get,

$$
\begin{aligned}
p\left(x_{n}, x_{n+s}\right) & \leq\left[p\left(x_{n}, x_{n+1}\right)+p\left(x_{n+1}, x_{n+2}\right)+\cdots+p\left(x_{n+s-1}, x_{n+s}\right)\right] \\
& =k^{n m}\left[1+k^{m}+\ldots+k^{(s-1) m}\right] p\left(x_{0}, T^{m}\left(x_{0}\right)\right) \\
& \leq \frac{k^{n m}}{1-k^{m}} p\left(x_{0}, T^{m}\left(x_{0}\right)\right)
\end{aligned}
$$

Thus,

$$
\lim _{n \rightarrow \infty} p\left(x_{n}, x_{n+s}\right)=0
$$

So $\left\{x_{n}\right\}$ is a Cauchy sequence in $X$. Since $X$ is $T$-orbitally complete, there is some $z \in X$ such that

$$
\lim _{n \rightarrow \infty} p\left(T^{m n}\left(x_{0}\right), z\right)=\lim _{n \rightarrow \infty} p\left(x_{n}, z\right)=p(z, z)=0 .
$$

Regarding Remark 1.7, the orbital continuity of $T$ implies that

$$
\begin{aligned}
p\left(T^{m}(z), T^{m}(z)\right) & =\lim _{n \rightarrow \infty} p\left(T^{m}\left(T^{n m}\left(x_{0}\right)\right), T^{m} z\right)=\lim _{n \rightarrow \infty} p\left(T^{m}\left(T^{n m}\left(x_{0}\right)\right), T^{m}\left(T^{n m}\left(x_{0}\right)\right)\right) \\
& =\lim _{n \rightarrow \infty}\left(T^{(n+1) m}\left(x_{0}\right), T^{m} z\right)=\lim _{n \rightarrow \infty}\left(T^{(n+1) m}\left(x_{0}\right), T^{(n+1) m}\left(x_{0}\right)\right), \\
& =\lim _{n \rightarrow \infty} p\left(x_{n+1}, T^{m} z\right)=\lim _{n \rightarrow \infty} p\left(x_{n+1}, x_{n+1}\right) \\
& =p\left(z, T^{m} z\right)=p(z, z)
\end{aligned}
$$

Thus $p\left(T^{m}(z), T^{m}(z)\right)=p\left(z, T^{m} z\right)=p(z, z)$. Regarding $(\mathrm{P} 1)$, the point $z$ is a periodic point of $T$.

Theorem 2.4. Let $T: X \rightarrow X$ be an orbitally continuous mapping on PMS $(X, d)$. Suppose that $T$ satisfies the condition

$$
\min \{p(x, T(x)), p(T(x), T(y)), p(T(y), y)\}<p(x, y)
$$

for all $x, y \in X, x \neq y$. If the sequence $\left\{T^{n}\left(x_{0}\right)\right\}$ has a cluster point $z \in X$ for some $x_{0} \in X$, then $z$ is a fixed point of $T$. 
Proof. Suppose $T^{m}\left(x_{0}\right)=T^{m-1}\left(x_{0}\right)$ for some $m \in \mathbb{N}$, then $T^{n}\left(x_{0}\right)=T^{m}\left(x_{0}\right)=z$ for all $n \geq m$. It is clear that $z$ is a required point.

Suppose $T^{m}\left(x_{0}\right) \neq T^{m-1}\left(x_{0}\right)$ for all $m \in \mathbb{N}$. Since $\left\{T^{n}\left(x_{0}\right)\right\}$ has a cluster point $z \in X$, one can write $\lim _{i \rightarrow \infty} T^{n_{i}}\left(x_{0}\right)=z$. By replacing $x$ and $y$ with $T^{n-1}\left(x_{0}\right)$ and $T^{n}\left(x_{0}\right)$, respectively, in 2.13 ,

$$
\begin{aligned}
& \min \left\{p\left(T^{n-1}\left(x_{0}\right), T\left(T^{n-1}\left(x_{0}\right)\right)\right), p\left(T\left(T^{n-1}\left(x_{0}\right)\right), T\left(T^{n}\left(x_{0}\right)\right)\right), p\left(T\left(T^{n}\left(x_{0}\right)\right), T^{n}\left(x_{0}\right)\right)\right\} \\
& <p\left(T^{n-1}\left(x_{0}\right), T^{n}\left(x_{0}\right)\right)
\end{aligned}
$$

The inequality $p\left(T^{n-1}\left(x_{0}\right), T^{n}\left(x_{0}\right)\right)<p\left(T^{n-1}\left(x_{0}\right), T^{n}\left(x_{0}\right)\right)$ does not hold. Thus, 2.14) is equivalent to $p\left(T^{n}\left(x_{0}\right), T^{n+1}\left(x_{0}\right)\right)<p\left(T^{n-1}\left(x_{0}\right), T^{n}\left(x_{0}\right)\right)$ which shows that the sequence

$$
\left\{p\left(T^{n}\left(x_{0}\right), T^{n+1}\left(x_{0}\right)\right)\right\}_{1}^{\infty}
$$

is decreasing and bounded below. Hence $\left\{p\left(T^{n}\left(x_{0}\right), T^{n+1}\left(x_{0}\right)\right)\right\}_{1}^{\infty}$ is convergent. By $T$-orbital continuity,

$$
\lim _{i \rightarrow \infty} p\left(T^{n_{i}}\left(x_{0}\right), T^{n_{i}+1}\left(x_{0}\right)\right)=p(z, T z) .
$$

Using $\left\{p\left(T^{n_{i}}\left(x_{0}\right), T^{n_{i}+1}\left(x_{0}\right)\right)\right\}_{1}^{\infty} \subset\left\{p\left(T^{n}\left(x_{0}\right), T^{n+1}\left(x_{0}\right)\right)\right\}_{1}^{\infty}$ and 2.16 , we have

$$
\lim _{n \rightarrow \infty} p\left(T^{n}\left(x_{0}\right), T^{n+1}\left(x_{0}\right)\right)=p(z, T z) .
$$

Considering the fact $\left\{p\left(T^{n_{i}+1}\left(x_{0}\right), T^{n_{i}+2}\left(x_{0}\right)\right)\right\}_{1}^{\infty} \subset\left\{p\left(T^{n}\left(x_{0}\right), T^{n+1}\left(x_{0}\right)\right)\right\}_{1}^{\infty}$ together with the limits $\lim _{i \rightarrow \infty} T^{n_{i}+1}\left(x_{0}\right)=T z, \lim _{i \rightarrow \infty} T^{n_{i}+2}\left(x_{0}\right)=T^{2} z$ and 2.17 show that

$$
p\left(T z, T^{2} z\right)=p(z, T z)
$$

Assume $T z \neq z$, that is, $p(z, T z)>0$. So, one can replace $x$ and $y$ with $z$ and $T z$, respectively, in $(2.13)$ to obtain

$$
\{p(z, T(z)), p(T(z), T(T(z))), p(T(T(z)), T(z))\}<p(z, T(z)) .
$$

which yields that $p\left(T z, T^{2} z\right)<p(z, T z)$. But this contradicts 2.18). Thus, $T z=z$.

Theorem 2.5. Let $T: X \rightarrow X$ be an orbitally continuous mapping on T-orbitally complete PMS $(X, p)$ and $\varepsilon>0$. Suppose that $T$ satisfies the condition

$$
\text { if } 0<p(x, y)<\varepsilon \text {, then } \min \{p(x, T(x)), p(T(x), T(y)), p(T(y), y)\}<p(x, y)
$$

for all $x, y \in X$. If for some $x_{0} \in X$, the sequence $\left\{T^{n}\left(x_{0}\right)\right\}_{n=1}^{\infty}$ has a cluster point of $z \in X$, then $z$ is a periodic point of $T$.

Proof. Set $\lim _{i \rightarrow \infty} T^{n_{i}}\left(x_{0}\right)=z$, that is, for any $\varepsilon>0$ there exists $N_{0} \in \mathbb{N}$ such that $p\left(T^{n_{i}}\left(x_{0}\right), z\right)<\frac{\varepsilon}{2 K}$ for all $i>N_{0}$. Hence, by triangle inequality (P4),

$$
p\left(T^{n_{i}}\left(x_{0}\right), T^{n_{i+1}}\left(x_{0}\right)\right) \leq p\left(T^{n_{i}}\left(x_{0}\right), z\right)+p\left(z, T^{n_{i+1}}\left(x_{0}\right)\right)<\varepsilon
$$

Let us define the set

$$
M=\left\{j \in \mathbb{N}: p\left(T^{n}\left(x_{0}\right), T^{n+j}\left(x_{0}\right)\right)<\varepsilon \text { for some } n \in \mathbb{N}\right\}
$$

which is non-empty by the assumption of the theorem. Let $m=\min M$. We need to consider two cases: either $p\left(T^{n}\left(x_{0}\right), T^{n+m}\left(x_{0}\right)\right)=0$ for some $n \in \mathbb{N}$ or $p\left(T^{n}\left(x_{0}\right), T^{n+m}\left(x_{0}\right)\right)>0$ for all $n \in \mathbb{N}$. In the first case, we have $z=T^{n}\left(x_{0}\right)=T^{n+m}\left(x_{0}\right)=T^{m}\left(T^{n}\left(x_{0}\right)\right)=T^{m}(z)$. Therefore the assertion of the theorem follows.

Suppose $p\left(T^{n}\left(x_{0}\right), T^{n+m}\left(x_{0}\right)\right)>0$ for all $n \in \mathbb{N}$. Let $r \in \mathbb{N}$ be such that $p\left(T^{r}\left(x_{0}\right), T^{r+m}\left(x_{0}\right)\right)<\varepsilon$. If $m=1$, then replacing $x$ and $y$ with $T^{n}\left(x_{0}\right)$ and $T^{n+1}\left(x_{0}\right)$, respectively, in 2.20 one can obtain that

$$
\begin{aligned}
& \min \left\{p\left(T^{n}\left(x_{0}\right), T\left(T^{n}\left(x_{0}\right)\right)\right), p\left(T\left(T^{n}\left(x_{0}\right)\right), T\left(T^{n+1}\left(x_{0}\right)\right)\right), p\left(T\left(T^{n+1}\left(x_{0}\right)\right), T^{n+1}\left(x_{0}\right)\right)\right\} \\
& <p\left(T^{n}\left(x_{0}\right), T^{n+1}\left(x_{0}\right)\right)
\end{aligned}
$$


Since the case $p\left(T^{n}\left(x_{0}\right), T^{n+1}\left(x_{0}\right)\right)<p\left(T^{n}\left(x_{0}\right), T^{n+1}\left(x_{0}\right)\right)$ is impossible, the inequality in 2.21 turns into

$$
p\left(T^{n+1}\left(x_{0}\right), T^{n+2}\left(x_{0}\right)\right)<p\left(T^{n}\left(x_{0}\right), T^{n+1}\left(x_{0}\right)\right),
$$

that is, $\left\{p\left(T^{n}\left(x_{0}\right), T^{n+1}\left(x_{0}\right)\right)\right\}$ is decreasing for $n \geq r$. Thus, by a routine calculation, one can conclude that $T z=z$.

Assume that $m \geq 2$, that is, for every $n \in \mathbb{N}$,

$$
p\left(T^{n}\left(x_{0}\right), T^{n+1}\left(x_{0}\right)\right) \geq \varepsilon .
$$

By the orbital continuity of $T, \lim _{i \rightarrow \infty} T^{n_{i}+r}\left(x_{0}\right)=T^{r}(z)$ and 2.22 , one can get

$$
p\left(T^{r}(z), T^{r+1}(z)\right)=\lim _{i \rightarrow \infty} p\left(T^{n_{i}+r}\left(x_{0}\right), T^{n_{i}+r+1}\left(x_{0}\right)\right) \geq \varepsilon .
$$

for every $r \in \mathbb{N}$. Regarding 2.20 with the assumption $0<p\left(T^{j}\left(x_{0}\right), T^{j+m}\left(x_{0}\right)\right)<\varepsilon$ one can obtain,

$$
\begin{aligned}
& \min \left\{p\left(T^{j}\left(x_{0}\right), T^{j+1}\left(x_{0}\right)\right), p\left(T^{j+1}\left(x_{0}\right), T^{j+m+1}\left(x_{0}\right)\right), p\left(T^{j+m}\left(x_{0}\right), T^{j+m+1}\left(x_{0}\right)\right)\right\} \\
& <p\left(T^{j}\left(x_{0}\right), T^{j+m}\left(x_{0}\right)\right)
\end{aligned}
$$

Thus, due to 2.22, we find $p\left(T^{j+1}\left(x_{0}\right), T^{j+m+1}\left(x_{0}\right)\right)<p\left(T^{j}\left(x_{0}\right), T^{j+m}\left(x_{0}\right)\right)<\varepsilon$. Continuing this process yields that

$$
\cdots<p\left(T^{j+2}\left(x_{0}\right), T^{j+m+2}\left(x_{0}\right)\right)<p\left(T^{j+1}\left(x_{0}\right), T^{j+m+1}\left(x_{0}\right)\right)<p\left(T^{j}\left(x_{0}\right), T^{j+m}\left(x_{0}\right)\right)<\varepsilon .
$$

Hence, the sequence $\left\{p\left(T^{n}\left(x_{0}\right), T^{n+m}\left(x_{0}\right)\right): n \geq j\right\}$ is decreasing and thus is convergent. Notice that the subsequence $\left\{p\left(T^{n_{i}}\left(x_{0}\right), T^{n_{i}+m}\left(x_{0}\right)\right): i \in \mathbb{N}\right\}$ and $\left\{p\left(T^{n_{i}+1}\left(x_{0}\right), T^{n_{i}+1+m}\left(x_{0}\right)\right): i \in \mathbb{N}\right\}$ are convergent to $d\left(z, T^{m} z\right)$ and $d\left(T z, T^{m+1} z\right)$, respectively. By the orbital continuity of $T$ and $\lim _{i \rightarrow \infty} T^{n_{i}}\left(x_{0}\right)=z$, one can get

$$
p\left(T(z), T^{m+1}(z)\right)=p\left(z, T^{m}(z)\right)=\lim _{n \rightarrow \infty} p\left(T^{n}\left(x_{0}\right), T^{n+m}\left(x_{0}\right)\right) .
$$

Therefore, one can conclude that $p\left(z, T^{m} z\right)<\varepsilon$ from $(2.24)$ and $(2.25)$. If $p\left(z, T^{m} z\right)=0$, then $T^{m} z=z$. Thus, the desired result is obtained. Suppose $p\left(z, T^{m} z\right)>0$. Apply 2.20$)$,

$$
\min \left\{p(z, T(z)), p\left(T(z), T\left(T^{m}(z)\right)\right), p\left(T\left(T^{m}(z)\right), T^{m}(z)\right)\right\}<p\left(z, T^{m} z\right)<\varepsilon
$$

Taking 2.23), 2.26) into the account yields that $p\left(T(z), T^{m+1}(z)\right)<p\left(z, T^{m} z\right)$ which contradicts with 2.25. Thus, $p\left(z, T^{m} z\right)=0$, and so $T^{m} z=z$.

Theorem 2.6. Let $T: X \rightarrow X$ be an orbitally continuous mapping on T-orbitally complete PMS $(X, p)$. Suppose that $T$ satisfies the condition

$$
\min \left\{[p(x, T(x))]^{2}, p(x, y) p(T(x), T(y)),[p(T(y), y)]^{2}\right\} \leq k p(x, T(x)) p(T(y), y)
$$

for all $x, y \in X$ and for some $k<1$. Then, for each $x \in X$, the iterated sequence $\left\{T^{n}(x)\right\}$ converges to a fixed point of $T$.

Proof. As in the proof of Theorem 2.9, fix $x_{0} \in X$ and define the sequence $\left\{x_{n}\right\}$ in the following way: For $n \geq 1$ set $x_{1}=T\left(x_{0}\right)$ and recursively $x_{n+1}=T\left(x_{n}\right)=T^{n+1}\left(x_{0}\right)$. It is clear that the sequence $x_{n}$ is Cauchy when the equality $x_{n+1}=x_{n}$ holds for some $n \in \mathbb{N}$. Consider the case $x_{n+1} \neq x_{n}$ for all $n \in \mathbb{N}$. By replacing $x$ and $y$ with $x_{n-1}$ and $x_{n}$, respectively, in (2.27), one can get

$$
\begin{aligned}
& \min \left\{\left[p\left(x_{n-1}, T\left(x_{n-1}\right)\right)\right]^{2}, p\left(x_{n-1}, x_{n}\right) p\left(T\left(x_{n-1}\right), T\left(x_{n}\right)\right),\left[p\left(T\left(x_{n}\right), x_{n}\right)\right]^{2}\right\} \\
& \leq k p\left(x_{n-1}, T\left(x_{n-1}\right)\right) p\left(T\left(x_{n}\right), x_{n}\right) .
\end{aligned}
$$


Since $k<1$, the case $p\left(x_{n-1}, x_{n}\right) p\left(x_{n}, x_{n+1}\right) \leq k p\left(x_{n-1}, x_{n}\right) p\left(x_{n}, x_{n+1}\right)$ gives a contradiction. Thus, one gets

$$
p\left(x_{n}, x_{n+1}\right) \leq k p\left(x_{n-1}, x_{n}\right) .
$$

Recursively, one can observe that

$$
p\left(x_{n}, x_{n+1}\right) \leq k p\left(x_{n-1}, x_{n}\right) \leq k^{2} p\left(x_{n-2}, x_{n-1}\right) \leq \cdots \leq k^{n} p\left(x_{0}, T\left(x_{0}\right)\right) .
$$

By a routine calculation performed as in the proof of Theorem 2.9, one can show that $\mathrm{T}$ has a fixed point.

Theorem 2.7. Let $X$ be a non-empty set endowed in two partial metrics $p$ and $\rho$. Let $T$ be a mapping of $X$ into itself. Suppose that

(i) $X$ is orbitally complete space with respect to $p$,

(ii) $p(x, y) \leq \rho(x, y)$ for all $x, y \in X$,

(iii) $T$ is orbitally continuous with respect to $p$,

(iv) T satisfies:

$$
\min \left\{[\rho(T(x), T(y))]^{2}, \rho(x, y) \rho(T(x), T(y)),[\rho(y, T(y))]^{2}\right\} \leq k \rho(x, T(x)), \rho(y, T y)
$$

for all $x, y \in X$, where $0 \leq k<1$.

Then $T$ has a fixed point in $X$.

Proof. As in the proof of Theorem 2.9. fix $x_{0} \in X$ and define the sequence $\left\{x_{n}\right\}$ in the following way: For $n \geq 1$ set $x_{1}=T\left(x_{0}\right)$ and recursively $x_{n+1}=T\left(x_{n}\right)=T^{n+1}\left(x_{0}\right)$. Replacing $x, y$ with $x_{n-1}, x_{n}$, respectively, in 2.29, one can get

$$
\begin{aligned}
& \min \left\{\left[\rho\left(T\left(x_{n-1}\right), T\left(x_{n}\right)\right)\right]^{2}, \rho\left(x_{n-1}, x_{n}\right) \rho\left(T\left(x_{n-1}\right), T\left(x_{n}\right)\right),\left[\rho\left(x_{n}, T\left(x_{n}\right)\right)\right]^{2}\right\} \\
& \leq k \rho\left(x_{n-1}, T\left(x_{n-1}\right)\right), \rho\left(x_{n}, T\left(x_{n}\right)\right) .
\end{aligned}
$$

Because of the inequality $k \rho\left(x_{n-1}, T\left(x_{n-1}\right)\right), \rho\left(x_{n}, T\left(x_{n}\right)\right) \leq k \rho\left(x_{n-1}, T\left(x_{n-1}\right)\right), \rho\left(x_{n}, T\left(x_{n}\right)\right)$, the expression in 2.30 is equivalent to $\rho\left(x_{n}, x_{n+1}\right) \leq k \rho\left(x_{n-1}, x_{n}\right)$. Recursively one can obtain

$$
\rho\left(x_{n}, x_{n+1}\right) \leq k \rho\left(x_{n-1}, x_{n}\right) \leq \cdots \leq k^{n} \rho\left(x_{0}, x_{1}\right) .
$$

Regarding the triangle inequality (P4), 2.31) implies that

$$
\rho\left(x_{n}, x_{n+s}\right) \leq \frac{k^{n}}{1-k} \rho\left(x_{0}, x_{1}\right) .
$$

for any $s \in \mathbb{N}$. Taking $(i i)$ of the theorem into the account, one can get

$$
p\left(x_{n}, x_{n+p}\right) \leq \frac{k^{n}}{1-k} \rho\left(x_{0}, x_{1}\right) .
$$

Thus, $\left\{x_{n}\right\}$ is a Cauchy sequence with respect to $p$. Since $X$ is $T$-orbitally complete, there exists $z \in X$ such that $\lim _{n \rightarrow \infty} T^{n}(x)=z$. From the orbital continuity of $T$, one can get the desired result, that is,

$$
T z=\lim _{n \rightarrow \infty} T\left(T^{n}(x)\right)=z .
$$

Remark 2.8. The fixed point theorems presented in this paper give conditions only for the existence of fixed points but not uniqueness. 


\section{References}

[1] T. Abdeljawad, E. Karapınar and K. Taş, A generalized contraction principle with control functions on partial metric spaces, Comput. Math. Appl., 63 (2012), 716-719. 1

[2] T. Abedelljawad, E. Karapınar and K. Taş, Existence and uniqueness of common fixed point on partial metric spaces, Appl. Math. Lett., 24 (2011), 1894-1899. 1

[3] J.Achari, On Ćirić's non-unique fixed points, Mat. Vesnik, 13 (1976), 255-257. 1 ]

[4] J. Achari, Results on non-unique fixed points, Publications de L'Institut Mathématique ,26 (1978), 5-9 . 1

[5] I. Altun, F. Sola and H. Şimşek, Generalized contractions on partial metric spaces, Topology and its Applications, 157 (2010), 2778-2785. 1

[6] I. Altun and A. Erduran, Fixed point theorems for monotone mappings on partial metric spaces, Fixed Point Theory and Applications 2011 (2011), Article ID 508730, 10 pages. 1 1

[7] H. Aydi, E. Karapinar, W. Shatnawi, Coupled fixed point results for $(\psi-\phi)$-weakly contractive condition in ordered partial metric spaces, Comput. Math. Appl., 62 (2011), 4449-4460. 1

[8] S. Banach, Sur les operations dans les ensembles abstraits et leur application aux equations integrales, Fund. Math. ,3 (1922), 133-181. 1

[9] J.Caristi, Fixed point theorems for mapping satisfying inwardness conditions, Trans. Amer. Math. Soc., 215 (1976), 241-251. 1

[10] K. P. Chi, E. Karapınar, T. D. Thanh, A generalized contraction principle in partial metric spaces, Math. Comput. Modelling, 55 (2012), 1673-1681. 1

[11] Lj. B.Ćirić , On some maps with a nonunique fixed point, Publ. Inst. Math., 17 (1974), 52-58 . 1

[12] Lj. B. Ćirić, On some maps with a nonunique fixed point, Publications de L'Institut Mathématique ,17 (1974), 52-58. 1, 1.6, 1 .

[13] S.Gupta and B.Ram, Non-unique fixed point theorems of Ćirić type, (Hindi) Vijnana Parishad Anusandhan Patrika 41 (1998), 217-231. 1

[14] T.L.Hicks, Fixed point theorems for quasi-metric spaces, Math. Japonica, 33 (1988), no:2, 231-236 . 1

[15] D Ilić, V. Pavlović and V. Rakocecić, Some new extensions of Banach's contraction principle to partial metric space, Appl. Math. Lett., 24 (2011),no:8, 1326-1330. 1

[16] S. Janković, , Z. Kadelburg, Z. and S. Radenović, On cone metric spaces: A survey, Nonlinear Anal., 74 (2011), 2591-2601. 1

[17] E. Karapinar, I. M. Erhan, Fixed point theorems for operators on partial metric spaces, Appl. Math. Lett., 24 (2011), 1900-1904. 1, 1.2

[18] E. Karapinar, Fixed Point Theorems in Cone Banach Spaces, Fixed Point Theory Appl., 2009 (2009), Article ID 609281, 9 pages doi:10.1155/2009/609281. 1

[19] E. Karapinar, Generalizations of Caristi Kirk's Theorem on Partial Metric Spaces, Fixed Point Theory Appl., 2011:4. 1

[20] E. Karapınar, Some Fixed Point Theorems on the class of comparable partial metric spaces on comparable partial metric spaces, Appl. Gen. Topol., 12 (2011), 187-192. 1

[21] E. Karapinar, Weak $\phi$-contraction on partial metric spaces, J. Comput. Anal. Appl., 14 (2012), 206-210. 1

[22] E. Karapinar, A new non-unique fixed point theorem, J. Appl. Funct. Anal., 7 (2012), 92-97. 1 ]

[23] R. Kopperman, S.G. Matthews, and H. Pajoohesh, What do partial metrics represent?, Spatial representation: discrete vs. continuous computational models, Dagstuhl Seminar Proceedings, No. 04351, Internationales Begegnungs- und Forschungszentrum für Informatik (IBFI), Schloss Dagstuhl, Germany, (2005). 1

[24] O. Kramosil and J. Michalek, Fuzzy metric and statistical metric spaces, Kybernetika, 11 (1975), 326-334 . 1

[25] H.P.A. Künzi, H. Pajoohesh, and M.P. Schellekens, Partial quasi-metrics, Theoret. Comput. Sci., 365 (2006), no:3, 237-246. 1 ]

[26] Liu, Z. Q.: On Cirić type mappings with a nonunique coincidence points, Mathematica (Cluj) 35 (1993), 221-225. 1

[27] Z. Liu, Z. Guo, S. M. Kang, and S. K. Lee, On Ćirić type mappings with nonunique fixed and periodic points, Int. J. Pure Appl. Math., 26 (2006), no: 3, 399-408. 1

[28] S. G. Matthews, Partial metric topology, Research Report 212, Dept. of Computer Science, University of Warwick, (1992). 1, 1, 1.2, 1, 2.2

[29] S. G. Matthews, Partial metric topology, Proc. 8th Summer Conference on General Topology and Applications, Annals of the New York Academi of Sciences, 728 (1994), 183-197. 1, 1.2, $1,2.2$

[30] K. Menger, Statistical metrics, Proc. Nat. Acad. Sci. USA, 28 (1942), 535-537. 1

[31] S.J. O'Neill, Two topologies are better than one, Tech. report, University of Warwick, Coventry, UK, (1995). 1

[32] S. Oltra, O. Valero, Banach's fixed point theorem for partial metric spaces, Rend. Istit. Mat. Univ. Trieste., 36 (2004), 17-26. 1

[33] O. Valero, On Banach fixed point theorems for partial metric spaces, Appl. Gen. Topol., 6 (2005) 229-240. 1

[34] Pachpatte, B. G.: On Ćirić type maps with a nonunique fixed point, Indian J. Pure Appl. Math., 10 (1979), 1039-1043. 1 
[35] S. Romaguera and M. Schellekens, Weightable quasi-metric semigroup and semilattices, Electronic Notes of Theoretical computer science, Proceedings of MFCSIT, 40, Elsevier, (2003). 1

[36] M.P. Schellekens, A characterization of partial metrizability: domains are quantifiable, Topology in computer science (Schlo Dagstuhl, 2000), Theoret. Comput. Sci., 305 (2003), 409-432. 1

[37] F. Zhang, S. M. Kang, and L. Xie, On Ćirić type mappings with a nonunique coincidence points, Fixed Point Theory Appl., 6 (2007), 187-190. 1 